\title{
Changes in Phenotypic Patterns of Blood Monocytes After Kidney Transplantation and During Acute Rejection
}

\author{
Veronika ŠVACHOVÁ ${ }^{1}$, Lenka KRUPIČKOVÁ ${ }^{1}$, Marek NOVOTNÝ ${ }^{2}$, Martina FIALOVÁ ${ }^{1}$, \\ Kristýna MEZEROVÁ ${ }^{1}$, Eva ČEČRDLOVA ${ }^{1}$, Věra LÁNSKÁ ${ }^{3}$, Antonij SLAVČEV ${ }^{1}$, Ondřej \\ VIKLICKÝ ${ }^{2}$, Ilja STŘíž ${ }^{1}$
}

${ }^{1}$ Department of Clinical and Transplant Immunology, Institute for Clinical and Experimental Medicine, Prague, Czech Republic, ${ }^{2}$ Department of Nephrology, Transplant Centre, Institute for Clinical and Experimental Medicine, Prague, Czech Republic, ${ }^{3}$ Department of Statistics, Institute for Clinical and Experimental Medicine, Prague, Czech Republic

Received April 4, 2021

Accepted May 26, 2021

Epub Ahead of Print September 10, 2021

\section{Summary}

Peripheral blood monocytes, which serve as precursors for tissue macrophages and dendritic cells (DC), play a key role in the immune response to kidney allograft, reparation processes and homeostasis regulation. In this prospective study, we used multicolor flow cytometry to monitor the phenotypic patterns of peripheral monocytes in subjects with uncomplicated outcomes and those with acute rejection. We found a reciprocal increase in the proportion of "classical monocytes" (CD14+CD16-) along with a decline in pro-inflammatory "intermediary" (CD14+CD16+) and "non-classical" (CD14lowCD16+) monocytes in subjects with normal outcomes. In subjects with acute rejection, we observed no reduction in "intermediary" monocytes and no increase in "classical" monocytes. Patients with uncomplicated outcomes exhibited downregulated HLA-DR in all three monocyte subpopulations. However, non-classical monocytes were unaffected in subjects with acute rejection. Expression of CD47 was downregulated after transplantation, while patients with antibody-mediated rejection and donor-specific antibodies showed higher pre-transplant values. In monocytes isolated at the time of biopsy, CD47 expression was higher in individuals with acute rejection compared to patients with normal outcomes one year post-transplant. Expression of CD209 (DC-SIGN) and the proportion of $\mathrm{CD} 163+\mathrm{CD} 206+$ subpopulations were upregulated during the first week after kidney transplantation. CD209 was also upregulated in samples taken on the day of biopsy confirming acute rejection. Our data demonstrate that kidney allograft transplantation is associated with phenotypic changes in peripheral blood monocytes during acute rejection.

\section{Key words}

Monocytes • Subpopulations • CD14+CD16+ • Kidney transplantation • Acute rejection

\section{Corresponding author}

I. Striz, Department of Clinical and Transplant Immunology, Institute for Clinical and Experimental Medicine, Videnska 1958/9, 14021 Prague 4, Czech Republic. E-mail: ilja.striz@ikem.cz

\section{Introduction}

The initial response of the immune system to kidney allograft is triggered by the surgical procedure and ischemia-reperfusion injury (IRI), which is accompanied by the release of multiple cytokines and chemokines that regulate the influx of immune cells into the transplanted kidney. The exacerbation of these events can also contribute to the development of delayed graft function, which is associated with increased risk of acute rejection during the first year after transplantation (Gill et al. 2016). In addition to the allospecific adaptive immune response to donor HLA antigens, the activity of innate immune cells, particularly mononuclear phagocytes (monocytes, macrophages, dendritic cells) and NK cells, also seems to play an important role. Monocytes, which serve as precursors of various macrophages and dendritic cells, play a key role in effector mechanisms, helping to regulate both innate and adaptive immune responses. Several lines of evidence show that the monocyte 
population is not homogeneous. Monocyte cells are divided into different subpopulations based on phenotype (Ravenhill et al. 2020) and cell function (Gordon and Taylor 2005).

In peripheral blood monocytes, three subpopulations can be distinguished based on expression levels of the membrane antigens CD14 (a receptor for LPS and other bacterial cell-wall antigens) and CD16 (Fc $\gamma$ RIII). Classical monocytes are characterized by strong CD14 expression in the absence of CD16 (CD14++CD16-). Intermediate monocytes have slightly lower expression of CD14 and exhibit CD16 staining $(\mathrm{CD} 14+\mathrm{CD} 16+)$. Non-classical monocytes have low CD14 expression and higher CD16 membrane density (CD14lowCD16++) (Kawamura and Ohteki 2018).

CD14+CD16+ are a subpopulation of repeatedly activated (senescent) monocytes featuring shortened telomeres and increased inflammatory capacity (Merino et al. 2011). In our previous study, the proportion of CD14+CD16+ monocytes was downregulated immediately after kidney allograft transplantation (Sekerkova et al. 2014). In one study, higher pre-transplant numbers of CD14+CD16+ were found in patients at risk of acute rejection (van den Bosch et al. 2017).

HLA-DR is an MHC class II molecule expressed at high levels in different forms of mononuclear phagocytes, including monocytes. Decreased expression of HLA-DR in peripheral blood monocytes is one of the well-established immune hallmarks of sepsis (Monneret and Venet 2016), signaling a transition from the inflammatory state to immune suppression and paralysis. First observed in the late 1980s (Appel et al. 1989), this phenomenon has been recently confirmed by mass cytometry (CyTOF) findings (Gossez et al. 2018). HLA-DR-negative/low monocytes are associated with tumor-induced immunosuppression and are understood to be one of the populations that make up the myeloidderived suppressor cells (MDSC) (Mengos et al. 2019). In liver transplant recipients, lower expression of HLA-DR in monocytes is associated with higher risk of imminent bacterial sepsis (van den Berk et al. 1997). Downregulated CD47 (also known as integrin-associated protein (IAP)) is a membrane protein of the immunoglobulin superfamily that interacts with integrins, thrombospondins and signal-regulatory proteins (SIRPs) (Oldenborg 2013). In burn patients, CD47 expression in peripheral blood monocytes was found to be lower in individuals with multi-organ dysfunction syndrome (MODS) (Wang et al. 2011). However, no data on CD47 expression in the monocytes of transplant patients are available.

CD209, a membrane lectin (also known as dendritic cell-specific ICAM-3-grabbing non-integrin (DC-SIGN)) involved in dendritic cell migration and T-cell interactions, is a characteristic marker of monocyte-derived dendritic cells (Deluce-Kakwata-Nkor et al. 2018). During the differentiation of monocytes into dendritic cells, CD209 expression increases along with a reciprocal decline in CD14 expression (Bullwinkel et al. 2011). CD209 is also expressed in lymph node macrophages (Granelli-Piperno et al. 2005) and in in vitro-differentiated M2 macrophages (Tarique et al. 2015). Expression of CD209 by fresh peripheral blood monocytes is relatively low (Chometon et al. 2020). In one study, an approximate four-fold upregulation of CD209 was observed in the kidney biopsies of patients with clinical manifestation of acute T-cell mediated rejection compared to individuals on a subclinical course (Wohlfahrtova et al. 2015).

CD163, a marker of alternatively activated M2 tissue macrophages, downregulates the immune response by releasing anti-inflammatory cytokine IL-10 (Mayer et al. 2010). These cells are frequent in malignant tumors and are thought to contribute to the progression of malignancy by downregulating immune effector mechanisms. The percentage of CD163-positive monocytes in peripheral blood has been shown to be downregulated in patients with diabetic complications compared to those with uncomplicated outcomes (Min et al. 2016). Two studies reported an increase in the number of CD163 monocytes during the first week after kidney transplantation in both living donor transplant (Guillen-Gomez et al. 2014) and cadaveric kidney recipients (Sekerkova et al. 2014).

CD206 is a mannose receptor, predominantly expressed by macrophages and dendritic cells that binds to different microorganisms (Azad et al. 2014). It is also understood to be involved in the regulation of macrophage migration (Sturge et al. 2007). Like CD163, CD206 is understood to be a marker of M2 macrophages, including tumor-associated mononuclear phagocytes (Benner et al. 2019). Although the occurrence of CD206+ monocytes, which exhibit intracellular IL-23 and IL-10 positivity, is relatively low, they are reportedly upregulated in infections such as helminthiasis (Passos et al. 2017). To our knowledge, there are no data on CD206 expression in the monocytes of transplant patients.

The aims of this study, therefore, were to identify phenotypic patterns of peripheral blood monocytes in 
kidney allograft recipients, evaluate changes induced by transplantation, and determine potential biomarkers for discriminating patients at risk of acute rejection.

\section{Patients and Methods}

Patients

A total of 138 patients were enrolled as part of the study. All individuals underwent renal transplantation from deceased donors at our transplant center between January 2016 and October 2017. The characteristics of patients are shown in Table 1. All patients provided their informed consent and signed an agreement upon the performance of each biopsy. The study protocol was approved by the Ethics Committee of the Institute for Clinical and Experimental Medicine (ID 118099).

Table 1. The demographic characteristics and clinical features of study groups.

\begin{tabular}{lcc}
\hline & Normal outcome & Rejection \\
\hline Number of patients (n) & 94 & 44 \\
Type of acute rejection (n, \%) & & $16(36.4)$ \\
$\cdot$ cellular & & $13(29.5)$ \\
$\cdot$ humoral/DSA+ & & $15(34.1)$ \\
$\cdot$ humoral/DSA- & $61 / 33$ & $28 / 16$ \\
Gender (male/female) (n) & $58(22-80)$ & $54(23-79)$ \\
Recipient age (median, range) & $56.5(1-81)$ & $51(21-75)$ \\
Donor age (median, range) & $14(0-24)$ & $15(0-21)$ \\
Cold ischemia time (h) (median, range) & $10(0-98)$ & $10(0-92)$ \\
PRA* (\%) (median, range) & $3(1-6)$ & $3(0-6)$ \\
HLA mismatches (median, range) & & \\
DSA** positivity (n, \%) & $8(8.5)$ & $14(31.8)$ \\
$\quad$ preformed DSA & 0 & $5(11.4)$ \\
de novo DSA & & \\
Induction therapy (n, \%) & & $16(36.4)$ \\
basiliximab & $27(28.7)$ & $18(40.9)$ \\
ATG & $59(62.8)$ & $10(22.7)$ \\
ATG, PE, IVIG & $8(8.5)$ & $39(88.6)$ \\
Maintenance IS (n, \%) & & $5(11.4)$ \\
Tac, MMF, CS & $86(91.5)$ & $0(0)$ \\
Tac, KS & $5(5.3)$ & \\
mTOR, MMF, CS & $3(3.2)$ & \\
\hline
\end{tabular}

$*$ PRA=panel reactive antibodies, $* *$ DSA=donor specific antibodies.

Induction treatment and maintenance immunosuppression

All patients received induction treatment according to the center's immune risk-based protocol. Primary kidney transplant recipients with PRA $<20 \%$ and negative DSA received basiliximab $(n=43)$. Patients with PRA $>20 \%$ received rabbit anti-thymocyte globulin (ATG, cumulative dose $5-7 \mathrm{mg} / \mathrm{kg})(\mathrm{n}=77)$. Individuals confirmed as DSA- positive at the time of transplantation $(\mathrm{n}=18)$ underwent plasma exchange (PE) prior to transplantation in addition to intravenous immunoglobulin (IVIG) and ATG. The majority of patients $(n=125)$ were treated using triple maintenance therapy consisting of tacrolimus, mycophenolate mofetil and corticosteroids. Target trough levels of tacrolimus were $10-15 \mu \mathrm{g} / 1$ in the first month after transplantation, with continuous cessation to 4-6 $\mu \mathrm{g} / \mathrm{l}$ after the third month. Ten patients were placed on dual therapy with tacrolimus and corticosteroids. Three patients were converted to everolimus in combination with mycophenolate mofetil and corticosteroids early after transplantation.

\section{Histopathology and rejection phenotypes}

Kidney allograft biopsy samples were obtained using a percutaneous ultrasound-guided $16 \mathrm{G}$ biopsy needle 
for for-cause or protocol biopsy, procedures routinely performed 3 months post-transplant in our center. All patients provided their informed consent and signed an agreement upon the performance of each biopsy.

Biopsy-proven acute rejection was diagnosed histologically according to the revised 2017 Banff classification (Haas et al. 2018). Out of 44 patients with acute rejection, 16 had $\mathrm{T}$ cell-mediated rejection characterized by tubulointerstitial inflammation or intimal arteritis in the absence of C4d and DSA. Twenty-eight patients had histological signs of antibody-mediated rejection such as glomerulitis, peritubular capillaritis and/or intimal arteritis in the presence of $\mathrm{C} 4 \mathrm{~d}$. The microvascular inflammation score was at least 2 in the absence of C4d. While DSA were detectable in 13 patients, they went undetected in the remaining 15 patients. Diagnosis of antibody-mediated rejection was based on histology.

The most frequent first-line treatments in patients with cellular rejection were pulsed methylprednisolone therapy (10 patients) and ATG (2 patients). In 3 steroid-resistant patients, ATG was used as a rescue therapy. Cases of DSA-positive humoral rejection were treated with methylprednisolone, plasma exchange and intravenous immunoglobulin ( 9 patients). Less intensive treatment involving solely methylprednisolone or adjusted maintenance immunosuppression was used in the remaining patients, mostly due to infectious complications. Eleven out of 13 DSA-negative patients with histological antibody-mediated rejection were treated with corticosteroids. PE and IVIG were added in 4 cases, with adjusted maintenance immunosuppression performed in 2 cases.

\section{Flow cytometry}

Peripheral blood mononuclear cells $(100 \mu 1$, approx. $1 \times 10^{6}$ ) were labelled with fluorochrome- conjugated monoclonal antibodies re-suspended in PBSBSA buffer for $20 \mathrm{~min}$ at room temperature (RT) in the dark. Monoclonal antibodies used in the study are shown in Table 2. Samples were measured on the Navios flow cytometer (Beckman Coulter, Brea, CA, USA) and analyzed using $\mathrm{CxP}$ and Kaluza software (Beckman Coulter, Brea, CA, USA). The percentage of positive cells and mean intensity fluorescence (MFI) were evaluated for each individual marker. The gating strategy is shown in Figures 1 and 2.

\section{Statistics}

Statistical analysis was performed using GraphPad Prism 5 software (GraphPad Software, La Jolla, CA, USA). Parametric or non-parametric (MannWhitney, Kruskal-Wallis) testing was used according to distribution. The $t$-test was used to analyse categorical variables. Logarithmical transformation and parametric testing was carried out using repeated measures ANOVA. The Bonferroni post hoc test was used to compare flow cytometry data between groups at different time-points. Clinical and flow cytometry data were correlated using Spearman's rank correlation coefficient. Differences were regarded statistically significant at $\mathrm{p}<0.05$.

\section{Results}

Distribution of CD14+CD16+ subpopulations after kidney allograft transplantation

The percentage of classical monocytes (CD14+CD16-) increased one week after transplantation. There was a slight decline after one month and further upregulation observed one year later. Exhibiting a completely opposite trend, the population of intermediate monocytes (CD14+CD16+) declined immediately after transplantation before upregulating one month later and declining one year post-transplant.

Table 2. Monoclonal antibodies used for immunophenotyping of monocytes.

\begin{tabular}{lccc}
\hline Fluorochrome & Marker & Clone & Producer \\
\hline FITC & CD47 & MEM-122 & Beckman Coulter, Brea, CA, USA \\
Pacific Blue & CD16 & $3 \mathrm{G} 8$ & Beckman Coulter, Brea, CA, USA \\
PC7 & HLA-DR & Immu-357 & Beckman Coulter, Brea, CA, USA \\
APC-Alexa Fluor 750 & CD14 & RM052 & Beckman Coulter, Brea, CA, USA \\
PerCP/Cy5.5 & CD209 & $9 \mathrm{E} 9 \mathrm{~A} 8$ & BioLegend, San Diego, CA, USA \\
PE & $\mathrm{CD} 163$ & GHI/61 & BioLegend, San Diego, CA, USA \\
APC & CD206 & $15-2$ & BioLegend, San Diego, CA, USA \\
\hline
\end{tabular}




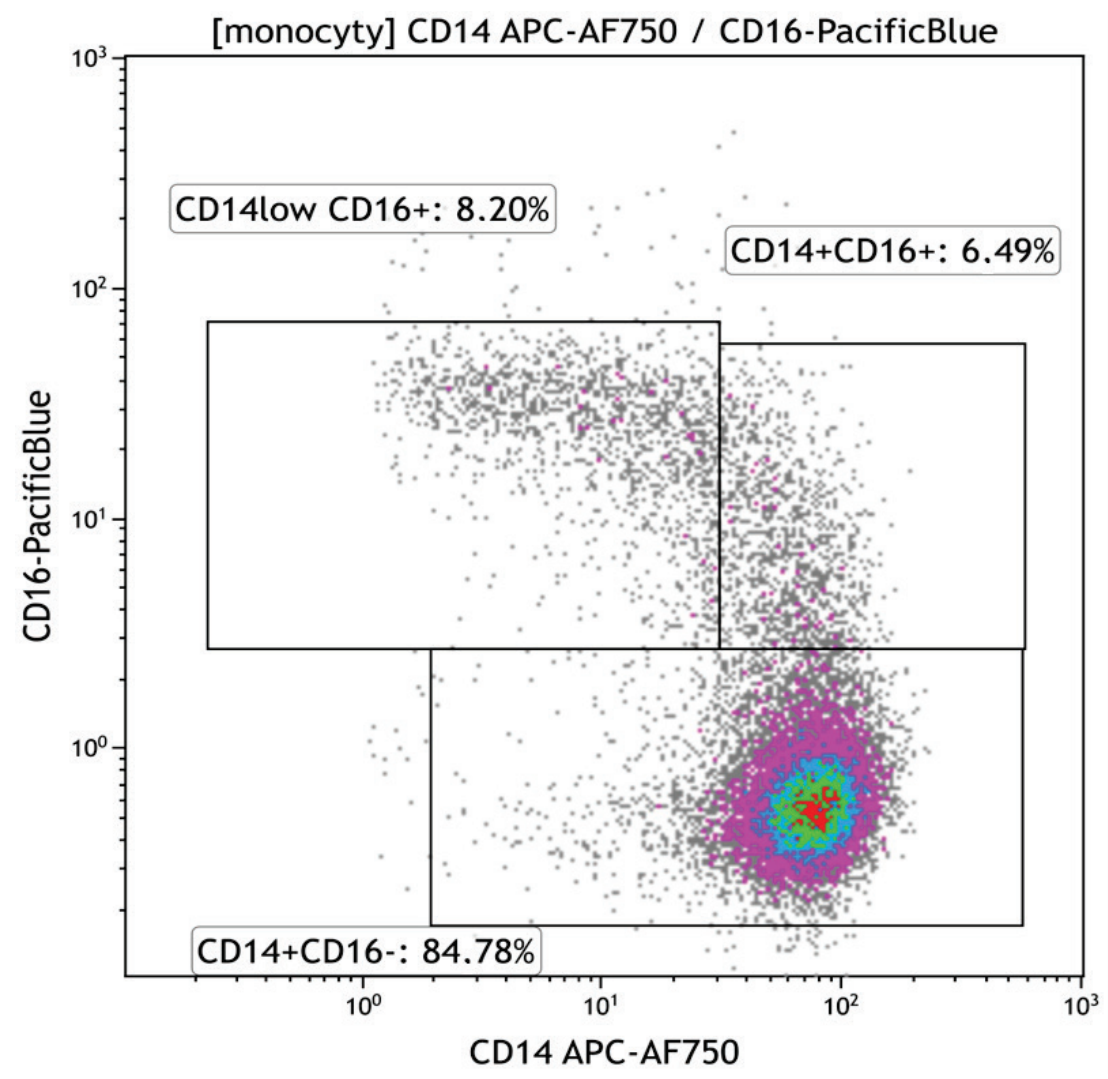

Fig. 1. Flow cytometry gating strategy for classical (CD14++CD16-), intermediary (CD14+CD16+) and non-classical (CD14lowCD16+) monocytes in peripheral blood of kidney transplant recipients.
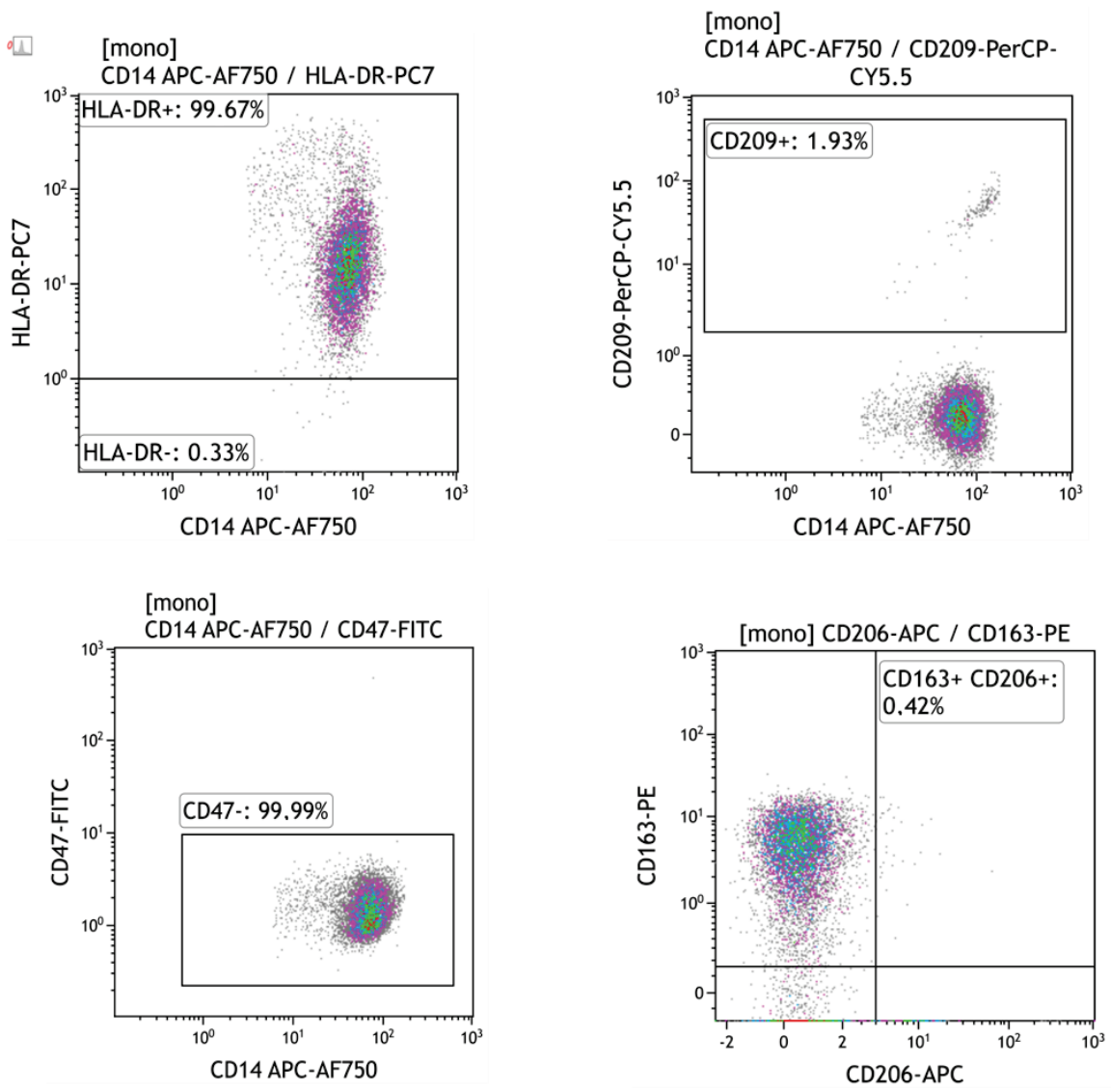

Fig. 2. Flow cytometry plot data showing the expression of HLA-DR, CD209, CD47, CD163 and CD206 in peripheral blood monocytes of kidney allograft recipients. 

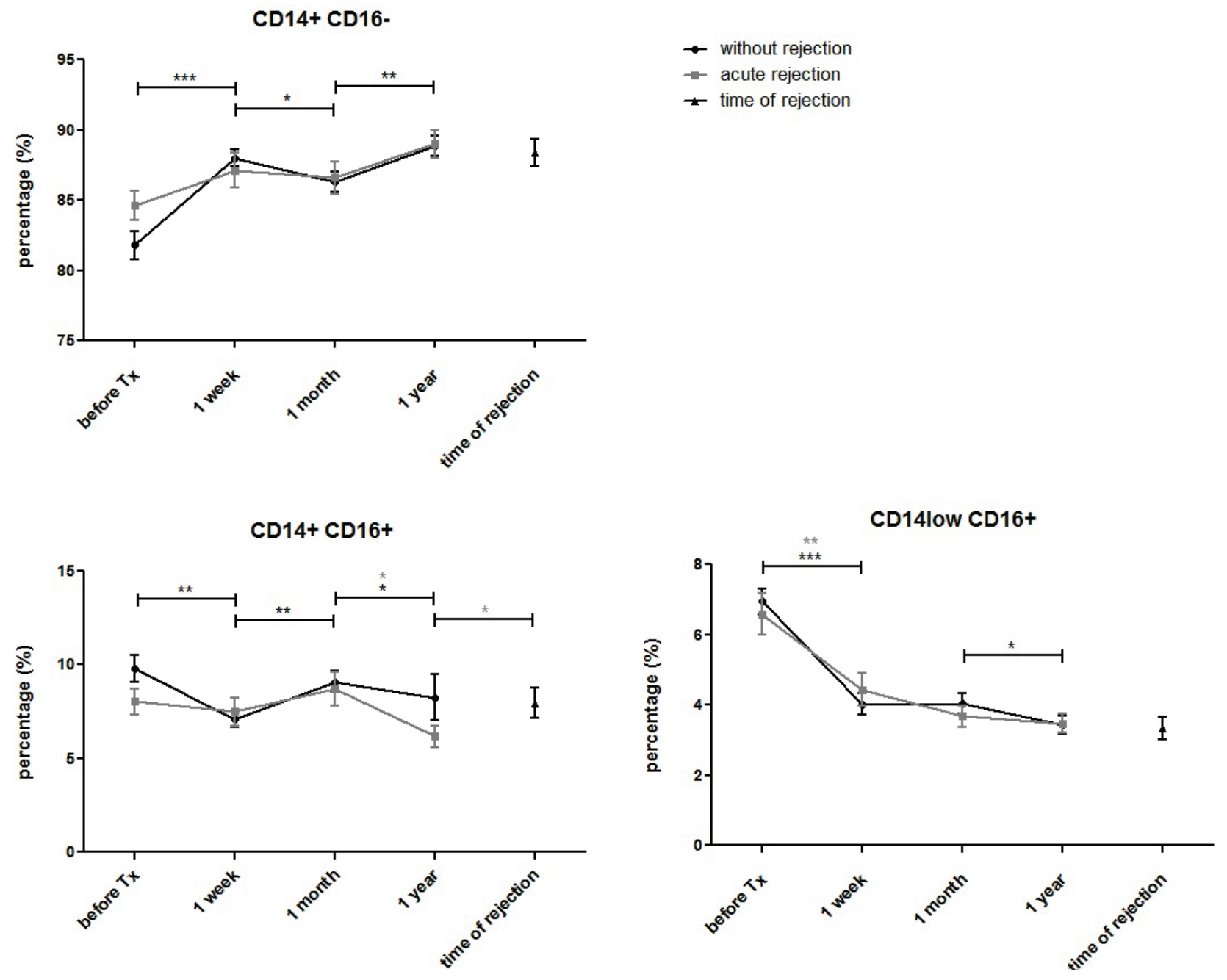

Fig. 3. Proportions of classical (CD14++CD16-), intermediary (CD14+CD16+) and non-classical (CD14lowCD16+) peripheral blood monocytes were measured before and one week, one month and one year after kidney allograft transplantation. Results from patients with uncomplicated outcomes $(n=94)$ were compared with those with acute rejection $(n=44)$. The number of CD14+CD16- monocytes increased immediately after transplantation, declined at one month and further upregulated one year post-transplant in both groups. The number of CD14+CD16+ monocytes decreased after transplantation, increased at one month and declined at one year. CD14lowCD16+ monocytes decreased dramatically after transplantation and remained lower than pre-transplant values, with a further decline at one year. In blood samples taken on the day of diagnostic biopsy confirming positive for acute rejection, no changes were observed compared to other post-transplant samples. Data are expressed as mean $\pm \mathrm{SEM} ; * \mathrm{p}<0.05$.

The percentages of non-classical monocytes (CD14lowCD16+) decreased dramatically during the first week after transplantation, remaining lower than pretransplant values and declining further by year one (Fig. 3). In blood samples taken on the day of diagnostic biopsy confirming positive for acute rejection, no changes in the proportions of monocyte subpopulations were observed compared to post-transplant samples taken from patients with normal outcomes or acute rejection.

\section{HLA-DR expression in monocytes of kidney allograft} recipients

HLA-DR expression in blood monocytes dramatically decreased one week after transplantation before returning to pre-transplant values one month later
(Fig. 4a). No changes were observed one year post-transplant. The same trend was observed in classical (CD14+CD16-) (Fig. 4b) and intermediate (CD14+CD16+) (Fig. 4c) monocytes. In non-classical (CD14lowCD16+) monocytes, a decline in HLA-DR after transplantation was observed in subjects with normal outcomes only. In contrast, no significant downregulation of HLA-DR was observed in patients with acute rejection (Fig. 4d). In blood samples taken on the day of biopsy confirming positive for acute rejection, higher expression of HLA-DR was observed in intermediate monocytes compared to expression in subjects with uncomplicated outcomes one year post-transplant. A decline in HLA-DR mean fluorescence after transplantation reflected the percentage of positive monocytes (Fig. 5). 

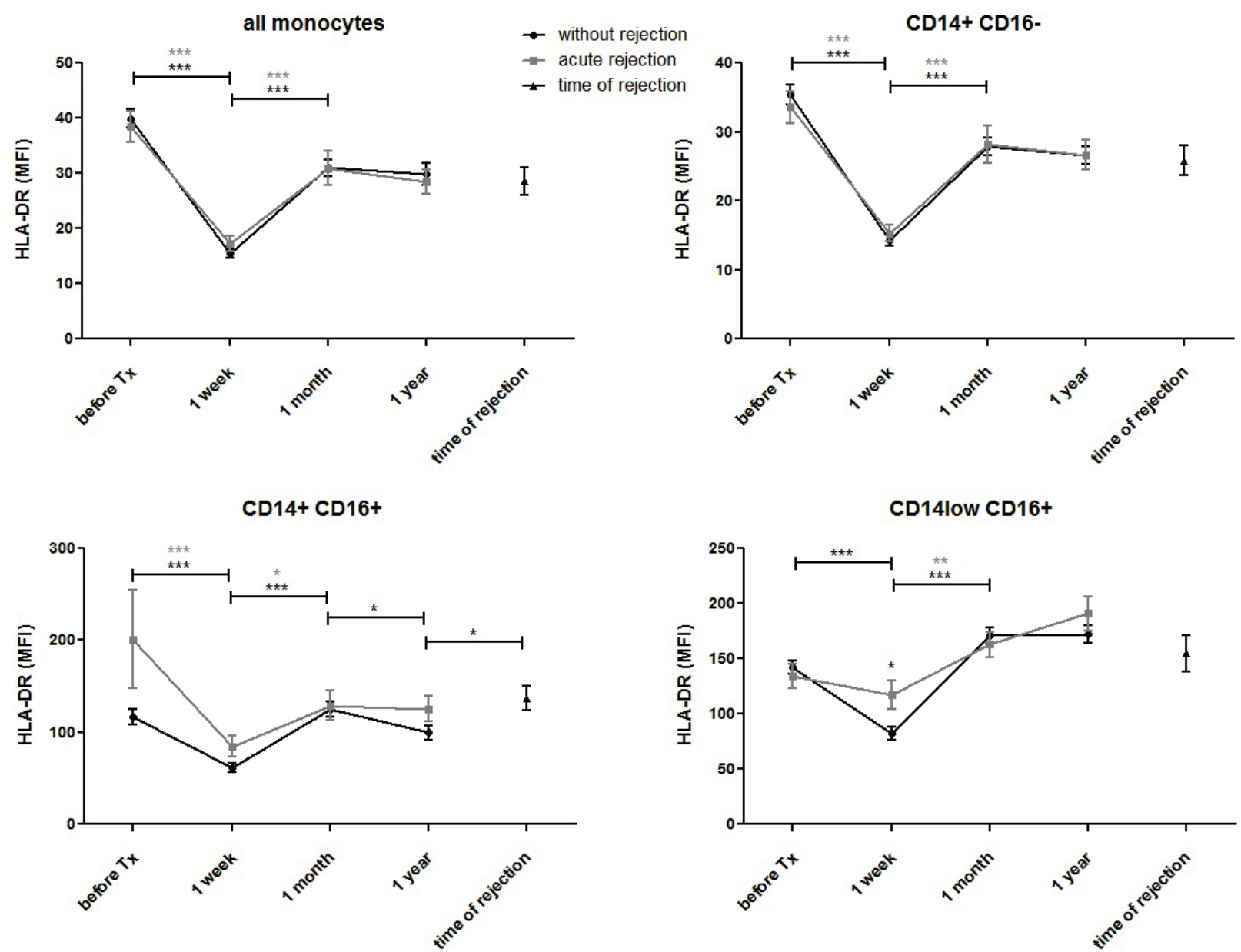

Fig. 4. HLA-DR expression was evaluated in classical (CD14+CD16-), intermediate (CD14+CD16+) and non-classical (CD14lowCD16+) peripheral blood monocytes obtained from patients with normal outcomes $(n=94)$ and those with acute rejection $(n=44)$ before and one week, one month, and one year after kidney transplantation surgery. In patients with acute rejection, additional data were obtained from blood on the day a positive diagnostic kidney biopsy was confirmed. HLA-DR-positive monocytes decreased after transplantation in both groups of patients. In non-classical (CD14low CD16+) monocytes, HLA-DR was downregulated after transplantation in subjects with normal outcomes. In contrast, no decline of HLA-DR was observed in patients with acute rejection. In blood taken on the day of biopsy confirming positive for acute rejection, higher expression of HLA-DR was found in intermediate monocytes compared to results from subjects with uncomplicated outcomes one year post-transplant. Data are expressed as mean $\pm \mathrm{SEM} ; * \mathrm{p}<0.05$.

\section{CD209 (DC-SIGN) expression in monocytes of kidney transplantation patients}

Expression of the dendritic cell lineage marker CD209 was upregulated one week after transplantation before downregulating to pre-transplant values one month post-transplant (Fig. 6). No differences between patients with normal outcomes and individuals with acute rejection were found. In samples collected at the time of acute rejection, CD209 expression in monocytes was higher compared to control samples taken one month $(p=0.018)$ and one year $(p=0.002)$ post-transplant.

\section{CD47 expression in monocytes of kidney transplant recipients}

Expression of the low-density CD47 antigen in blood monocytes downregulated during the first week after kidney transplantation before adjusting to pre-transplant values at one month (Fig. 7a). A further decrease in CD47 expression was observed one year post-transplant. Expression of CD47 in monocytes recorded at the time of acute rejection was higher compared to expression in subjects with normal outcomes one year post-transplant $(p<0.001)$. Patients with antibody-mediated rejection and DSA had higher pre-transplant expression of CD47 in peripheral blood monocytes (Fig. 7b).

\section{CD206+CD163+ monocytes after kidney allograft transplantation}

The percentage of this potentially immunesuppressive M2-like monocyte subpopulation increased early after transplantation (Fig. 8). In patients with normal outcomes, a further increase in the percentage of CD206+CD163 monocytes was observed one month post-transplant but not in subjects with acute rejection. 


\section{HLA-DR}

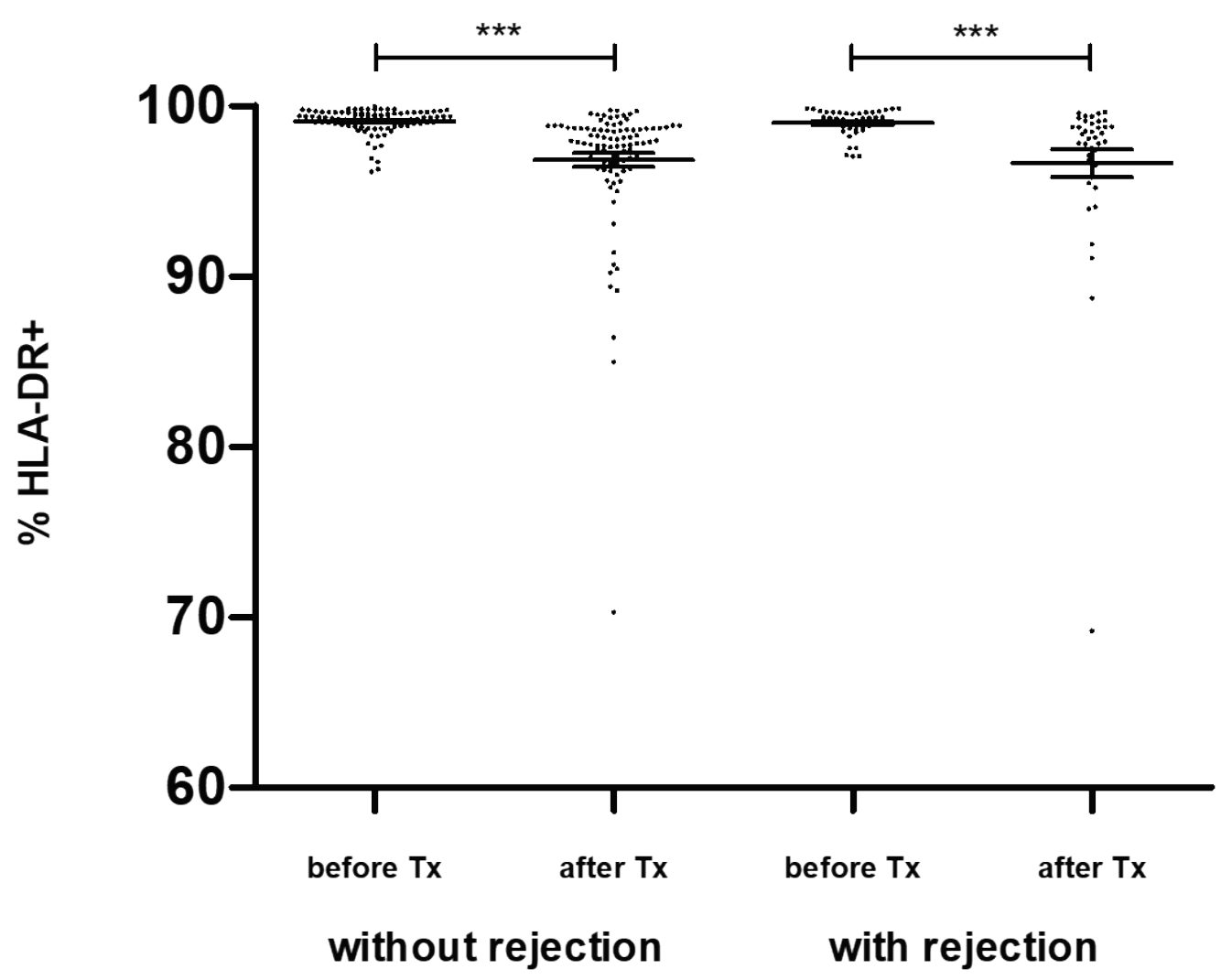

Fig. 5. Monocyte expression of HLA-DR was evaluated in kidney transplant patients with uncomplicated outcomes $(n=94)$ and those with acute rejection $(n=44)$ before and one week after surgery. Reductions in HLA-DR mean fluorescence in both groups one week post-transplant were also observed, reflecting the percentage of positive monocytes. Data are expressed as mean $\pm \mathrm{SEM} ; * * * \mathrm{p}<0.001$.

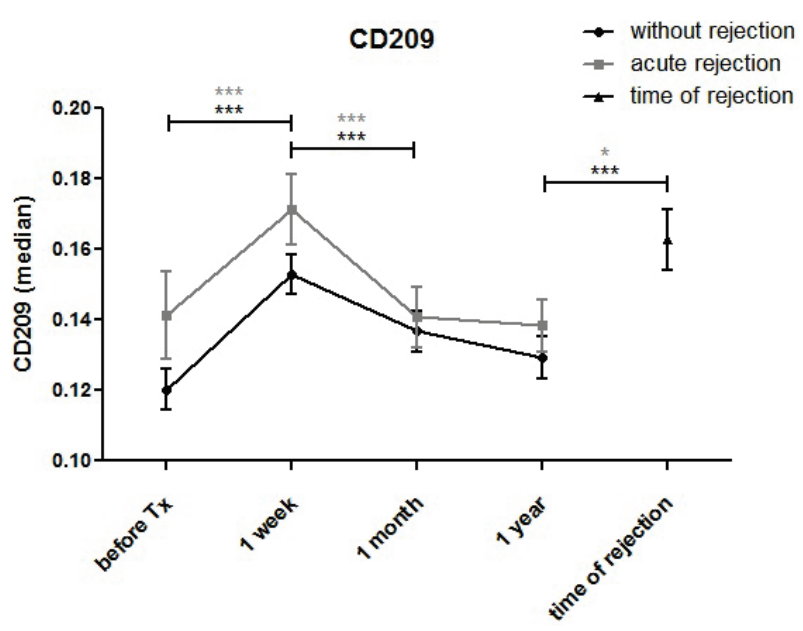

Fig. 6. CD209 expression in monocytes of kidney transplant patients with uncomplicated outcomes $(n=94)$ and those with acute rejection ( $n=44)$ was measured before and one week, one month and one year after surgery. CD209 expression increased one week after transplantation, subsequently declined at one month and further decreased (in patients with normal outcomes only) one year post-transplant. At the time of acute rejection, CD209 expression in monocytes was higher than in control samples taken at one month $(p=0.018)$ and one year $(p=0.002)$.

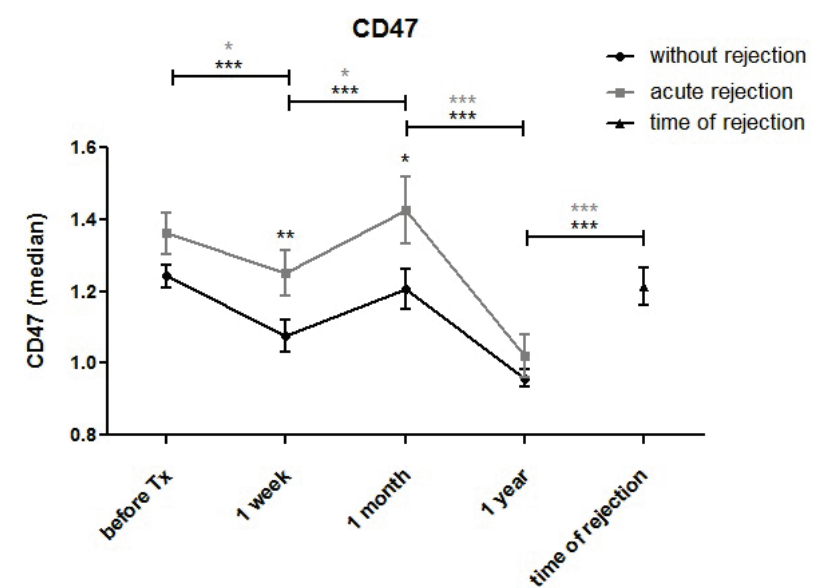

Fig. 7a. CD47 expression was evaluated in monocytes of kidney transplant patients with uncomplicated outcomes $(n=94)$ and those with acute rejection $(n=44)$ before and one week, one month, and one year after surgery. Monocyte CD47 expression decreased during the first week after kidney transplantation followed by a return to pre-transplant values at one month. In samples taken at one year, a decrease in CD47 expression was again observed. In monocytes obtained at the time of acute rejection, CD47 expression was higher compared to values in subjects with normal outcomes at one year $(p<0.001)$. 


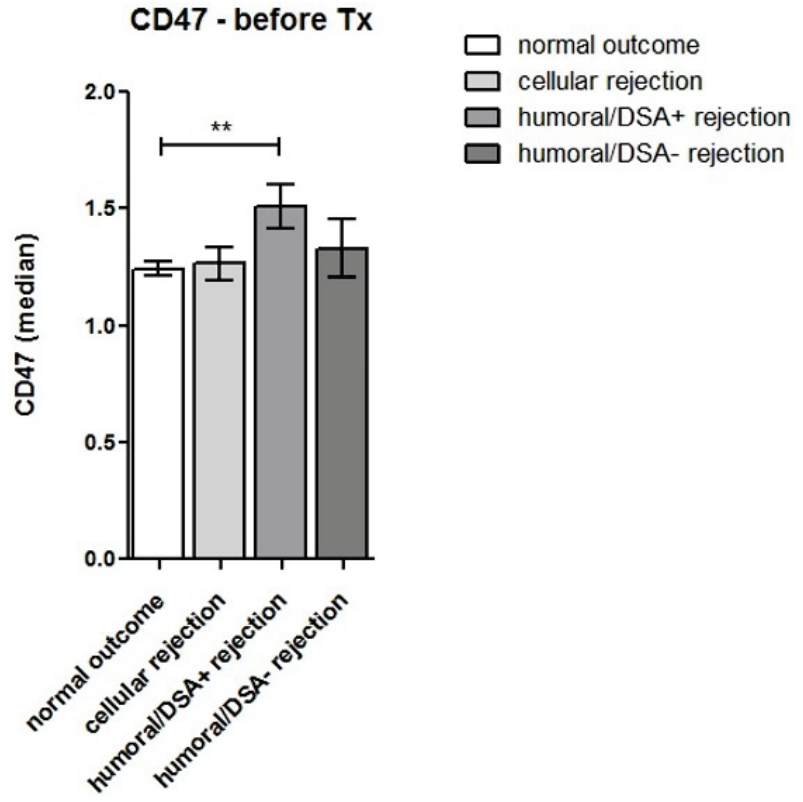

Fig. 7b. CD47 expression was evaluated in monocytes of kidney transplant recipients with uncomplicated outcomes $(n=94)$ and those with cellular rejection $(n=16)$, humoral rejection with donor-specific (DSA) antibodies $(n=13)$ and DSA-negative humoral rejection $(n=15)$ before and one week after transplantation. Kidney transplant patients with antibodymediated DSA-positive rejection showed higher pre-transplant expression of CD47 in peripheral blood monocytes compared to subjects with normal outcomes and other types of rejection.

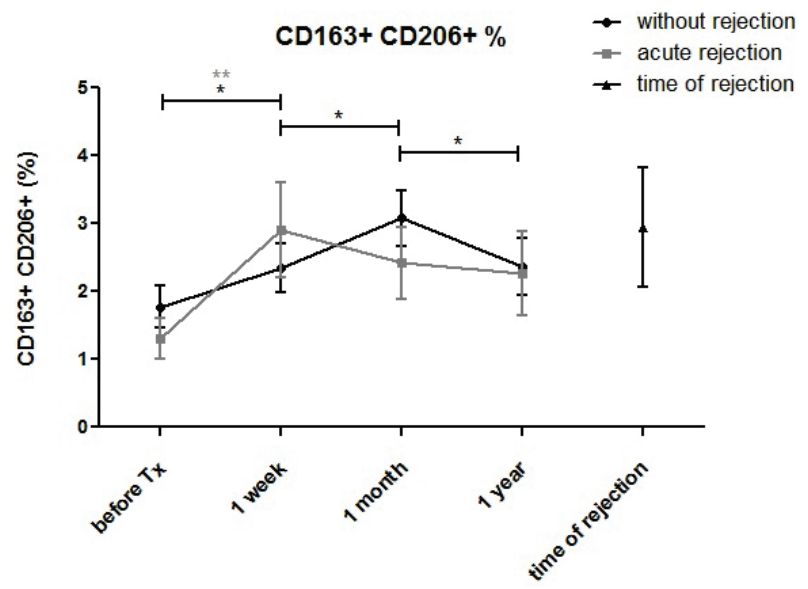

Fig. 8. Monocytes co-expressing CD163 and CD206 were measured in monocytes of kidney transplant patients with uncomplicated outcomes $(n=94)$ and those with acute rejection $(n=44)$ before and one week, one month and one year after surgery. The percentage of CD163+CD206+monocytes increased one week post-transplant in all subjects and further increased at one month only in patients with uncomplicated outcome and not in subjects with acute rejection.

\section{Discussion}

Our data not only demonstrate profound changes in the phenotypic patterns of peripheral blood monocytes after kidney allograft transplantation, but also highlight several differences between patients with uncomplicated outcomes and those with acute rejection. Previous findings of a decline in CD16+ monocytes shortly after kidney transplantation in recipients of allografts from both living (Vereyken et al. 2013) and deceased (Sekerkova et al. 2014) donors mostly apply to the nonclassical (CD14lowCD16+) monocyte subpopulation and to the intermediate subpopulation $(\mathrm{CD} 14+\mathrm{CD} 16+)$ to a lesser extent. Immunosuppression involving corticosteroids is a factor that can potentially affect the distribution of monocyte subpopulations. However, therapies consisting of mycophenolate mofetil, calcineurin inhibitors and mammalian target of rapamycin inhibitors (mTORI) are not understood to play a role (Rogacev et al. 2015). Our data confirmed no increase in pre-transplant numbers of CD16+ monocytes in subjects with acute rejection (van den Bosch et al. 2017). On the other hand, we did observe an increase in intermediate (CD14+CD16+) monocytes and a simultaneous decrease in classical (CD14+CD16-) monocytes in patients with acute rejection, which would seem to indicate the direct involvement of these cells. The numbers of $\mathrm{CD} 16+$ pro-inflammatory monocytes in circulation are associated not only with acute inflammation in, for example, septic patients (Gainaru et al. 2018), but also with cases of hypertriglyceridaemia (Xue et al. 2013) and subclinical atherosclerosis (Ulrich et al. 2008) in kidney transplant recipients.

A study monitoring HLA-DR-positive monocytes in kidney transplant recipients documented a decrease in the number of these monocytes two weeks after transplantation. However, changes in HLA-DR expression were not associated with acute rejection or CMV infection (Cho et al. 2015). We observed a similar decline in the numbers of HLA-DR-positive monocytes one week after transplantation. However, the nonclassical CD14lowCD16+ monocyte subpopulation was unaffected in patients with acute rejection. In subjects with normal outcomes, downregulated HLA-DR expression in this monocyte subpopulation was similar to expression in classical and intermediate monocytes. The absence of any post-transplant decrease in HLA-DR expression in pro-inflammatory non-classical monocytes in our acute rejection patients may have been caused by $\mathrm{I} / \mathrm{R}$ injury and the subsequent enhanced immune reaction to kidney allograft.

Our data revealed very low expression of CD209 in blood monocytes. A characteristic marker of dendritic cells CD209 was transiently upregulated during the first 
week after transplantation, but there were no differences between subjects with normal outcomes and those with acute rejection. On the other hand, CD209 was upregulated in monocytes confirmed as positive for acute rejection on the day of biopsy. This trend may reflect the involvement of sparse undifferentiated DC cells, since the induction of CD209 is accompanied by a simultaneous decline in CD14 expression (Chometon et al. 2020). One group of authors identified monocytes exhibiting CD14 and CD209 co-expression and adenosine membrane receptors as a pro-inflammatory subpopulation (Yuryeva et al. 2015), while another study found these monocytes to be increased in patients with $\mathrm{H}$. pylori-positive peptic ulcers (Hou et al. 2019). In this respect, upregulation of CD209 in response to kidney allograft is not surprising.

Expression of CD47, another low-density protein, was transiently downregulated in monocytes in the first week after transplantation and at one year. Patients with antibody-mediated rejection and DSA had higher pre-transplant expression of CD47 compared to patients with normal outcomes or other types of rejection. Monocyte CD47 expression was also higher in the biopsy blood samples of acute rejection patients. The CD47SIRP $\alpha$ interaction, a ubiquitously expressed "do not eat me" signal, has been extensively studied as a potential immune checkpoint for cancer immunotherapy (Veillette and Chen 2018, Strizova et al. 2020). But while the CD47-SIRP $\alpha$ axis interaction and gene polymorphisms of these proteins (Menon and Heeger 2017) seem to be involved in innate non-self recognition by monocytes (Zhao et al. 2020), their role in transplant settings is not yet clear. Monoclonal antibody blocking of CD47 has been shown to reduce IRI and subsequent tissue injury and improve renal function in experimental rat (Lin et al. 2014) and swine (Xu et al. 2018) kidney transplantation models. Conversely, an experimental model of long-term kidney allograft tolerance demonstrated that blocking anti-SIRP $\alpha$ and CD47 decreased numbers of MDSCs, which are associated with loss of tolerance, allograft dysfunction and rejection (Pengam et al. 2019).
Membrane expression of CD206 and CD163 is characteristic of a particular immunosuppressive M2 subset of tissue macrophages, including those found in the renal parenchyma ( $\mathrm{Hu}$ et al. 2019). The data on peripheral blood monocytes, however, are more scarce. A recent study found upregulation of CD163 during the first week after kidney allograft in all three monocyte subpopulations, including intermediate and non-classical subsets displaying pro-inflammatory properties (Curnova et al. 2020). Of the factors that regulate CD163 expression in blood monocytes in vitro, glucocorticoids, IL-10 and IL6 upregulate, (Maniecki et al. 2006) while pro-inflammatory stimuli such as TNF alpha, IFN gamma and LPS downregulate, the membrane form. Higher counts of CD163 $+\mathrm{CD} 206+$ monocytes have been found in the peripheral blood of patients with idiopathic membranous nephropathy (Hou et al. 2018) and also in septic patients (Brunialti et al. 2012). The CD206+CD163+ monocyte subpopulation is present in peripheral blood in low numbers, but moderately upregulates immediately after transplantation (probably in response to immunosuppressive therapy).

Our findings indicate that peripheral blood monocytes undergo complex phenotypic changes during the early phase after kidney allograft transplantation and that regulation of membrane expression in some antigens differs in patients with normal outcomes and those with acute rejection.

\section{Conflict of Interest}

There is no conflict of interest.

\section{Acknowledgements}

This work was supported by Ministry of Health of the Czech Republic, [Grant Nr. 15-26883A] and by Ministry of Health, Czech Republic - conceptual development of research organization ("Institute for Clinical and Experimental Medicine - IKEM, IN 00023001"). Authors are indebted to Eva Fáberová and Veronika Běhalová for their excellent technical assistance.

\section{References}

APPEL SH, WELLHAUSEN SR, MONTGOMERY R, DEWEESE RC, POLK HC JR: Experimental and clinical significance of endotoxin-dependent HLA-DR expression on monocytes. J Surgical Res 47: 39-44, 1989. https://doi.org/10.1016/0022-4804(89)90045-0

AZAD AK, RAJARAM MV, SCHLESINGER LS: Exploitation of the macrophage mannose receptor (CD206) in infectious disease diagnostics and therapeutics. J Cytol Mol Biol 1: 1000003, 2014. https://doi.org/10.13188/2325$\underline{4653.1000003}$ 
BENNER B, SCARBERRY L, SUAREZ-KELLY LP, DUGGAN MC, CAMPBELL AR, SMITH E, LAPURGA G, JIANG K, BUTCHAR JP, TRIDANDAPANI S, HOWARD JH, BAIOCCHI RA, MACE TA, CARSON WE 3RD: Generation of monocyte-derived tumor-associated macrophages using tumor-conditioned media provides a novel method to study tumor-associated macrophages in vitro. J Immunother Cancer 7: 140, 2019. https://doi.org/10.1186/s40425-019-0622-0

BRUNIALTI MK, SANTOS MC, RIGATO O, MACHADO FR, SILVA E, SALOMAO R: Increased percentages of T helper cells producing IL-17 and monocytes expressing markers of alternative activation in patients with sepsis. PLoS One 7: e37393, 2012. https://doi.org/10.1371/journal.pone.0037393

BULLWINKEL J, LUDEMANN A, DEBARRY J, SINGH PB: Epigenotype switching at the CD14 and CD209 genes during differentiation of human monocytes to dendritic cells. Epigenetics 6: 45-51, 2011. https://doi.org/10.4161/epi.6.1.13314

CHO J-H, YOON Y-D, JANG HM, KWON E, JUNG H-Y, CHOI J-Y, PARK S-H, KIM Y-L, KIM HK, HUH S, WON D-I, KIM C-D: Immunologic Monitoring of T-lymphocyte Subsets and Hla-Dr-Positive Monocytes in Kidney Transplant Recipients: A Prospective, Observational Cohort Study. Medicine (Baltimore) 94: e1902, 2015. https://doi.org/10.1097/MD.0000000000001902

CHOMETON TQ, SIQUEIRA MDS, SANT ANNA JC, ALMEIDA MR, GANDINI M, MARTINS DE ALMEIDA NOGUEIRA AC, ANTAS PRZ: A protocol for rapid monocyte isolation and generation of singular human monocyte-derived dendritic cells. PLoS One 15: e0231132, 2020. https://doi.org/10.1371/journal.pone.0231132

CURNOVA L, MEZEROVA K, SVACHOVA V, FIALOVA M, NOVOTNY M, CECRDLOVA E, VIKLICKY O, STRIZ I: Up-regulation of CD163 expression in subpopulations of blood monocytes after kidney allograft transplantation. Physiol Res 69: 885-896, 2020. https://doi.org/10.33549/physiolres.934531

DELUCE-KAKWATA-NKOR N, LAMENDOUR L, CHABOT V, HERAUD A, IVANOVIC Z, HALARY F, DEHAUT F, VELGE-ROUSSEL F: Differentiation of human dendritic cell subsets for immune tolerance induction. Transfus Clin Biol 25: 90-95, 2018. https://doi.org/10.1016/j.tracli.2017.08.002

GAINARU G, PAPADOPOULOS A, TSANGARIS I, LADA M, GIAMARELLOS-BOURBOULIS EJ, PISTIKI A: Increases in inflammatory and CD14(dim)/CD16(pos)/CD45(pos) patrolling monocytes in sepsis: correlation with final outcome. Crit Care 22: 56, 2018. https://doi.org/10.1186/s13054-018-1977-1

GILL J, DONG J, ROSE C, GILL JS: The risk of allograft failure and the survival benefit of kidney transplantation are complicated by delayed graft function. Kidney Int 89: 1331-1336, 2016. https://doi.org/10.1016/j.kint.2016.01.028

GORDON S, TAYLOR PR: Monocyte and macrophage heterogeneity. Nat Rev Immunol 5: 953-964, 2005. https://doi.org/10.1038/nri1733

GOSSEZ M, RIMMELE T, ANDRIEU T, DEBORD S, BAYLE F, MALCUS C, POITEVIN-LATER F, MONNERET G, VENET F: Proof of concept study of mass cytometry in septic shock patients reveals novel immune alterations. Sci Rep 8: 17296, 2018. https://doi.org/10.1038/s41598-018-35932-0

GRANELLI-PIPERNO A, PRITSKER A, PACK M, SHIMELIOVICH I, ARRIGHI JF, PARK CG, TRUMPFHELLER C, PIGUET V, MORAN TM, STEINMAN RM: Dendritic cell-specific intercellular adhesion molecule 3-grabbing nonintegrin/CD209 is abundant on macrophages in the normal human lymph node and is not required for dendritic cell stimulation of the mixed leukocyte reaction. J Immunol 175: 4265-4273, 2005. https://doi.org/10.4049/jimmunol.175.7.4265

GUILLÉN-GÓMEZ E, GUIRADO L, BELMONTE X, MADERUELO A, SANTÍN S, JUAREZ C, ARS E, FACUNDO C, BALLARÍN JA, VIDAL S, DÍAZ-ENCARNACIÓN MM: Monocyte implication in renal allograft dysfunction. Clin Exp Immunol 175: 323-331, 2014. https://doi.org/10.1111/cei.12228

HAAS M, LOUPY A, LEFAUCHEUR C, ROUFOSSE C, GLOTZ D, SERON D, NANKIVELL BJ, HALLORAN PF, COLVIN RB, AKALIN E, ALACHKAR N, BAGNASCO S, BOUATOU Y, BECKER JU, CORNELL LD, DUONG VAN HUYEN JP, GIBSON IW, KRAUS ES, MANNON RB, NAESENS M, ET AL.: The Banff 2017 Kidney Meeting Report: Revised diagnostic criteria for chronic active T cell-mediated rejection, antibody-mediated rejection, and prospects for integrative endpoints for next-generation clinical trials. Am J Transplant 18: 293-307, 2018. https://doi.org/10.1111/ajt.14625 
HOU J, WANG X, ZHANG M, WANG M, GAO P, JIANG Y: Circulating CD14(+)CD163(+)CD209(+) M2-like monocytes are associated with the severity of infection in Helicobacter pylori-positive patients. Mol Immunol 108: 13-22, 2019. https://doi.org/10.1016/j.molimm.2019.01.017

HOU J, ZHANG M, DING Y, WANG X, LI T, GAO P, JIANG Y: Circulating CD14(+)CD163(+)CD206(+) M2 monocytes are increased in patients with early stage of idiopathic membranous nephropathy. Mediators Inflamm 2018: 5270657, 2018. https://doi.org/10.1155/2018/5270657

HU W, LIN J, LIAN X, YU F, LIU W, WU Y, FANG X, LIANG X, HAO W: M2a and M2b macrophages predominate in kidney tissues and M2 subpopulations were associated with the severity of disease of IgAN patients. Clin Immunol 205: 8-15, 2019. https://doi.org/10.1016/j.clim.2019.05.005

KAWAMURA S, OHTEKI T: Monopoiesis in humans and mice. Int Immunol 30: 503-509, 2018. https://doi.org/10.1093/intimm/dxy063

LIN Y, MANNING PT, JIA J, GAUT JP, XIAO Z, CAPOCCIA BJ, CHEN C-C, HIEBSCH RR, UPADHYA G, MOHANAKUMAR T, FRAZIER WA, CHAPMAN WC: CD47 blockade reduces ischemia-reperfusion injury and improves outcomes in a rat kidney transplant model. Transplantation 98: 394-401, 2014. https://doi.org/10.1097/TP.0000000000000252

MANIECKI MB, MOLLER HJ, MOESTRUP SK, MOLLER BK: CD163 positive subsets of blood dendritic cells: the scavenging macrophage receptors CD163 and CD91 are coexpressed on human dendritic cells and monocytes. Immunobiology 211: 407-417, 2006. https://doi.org/10.1016/j.imbio.2006.05.019

MAYER A, LEE S, JUNG F, GRUTZ G, LENDLEIN A, HIEBL B: CD14+ CD163+ IL-10+ monocytes/macrophages: Pro-angiogenic and non pro-inflammatory isolation, enrichment and long-term secretion profile. Clin Hemorheol Microcirc 46: 217-223, 2010. https://doi.org/10.3233/CH-2010-1348

MENGOS AE, GASTINEAU DA, GUSTAFSON MP: The CD14(+)HLA-DR(lo/neg) Monocyte: An immunosuppressive phenotype that restrains responses to cancer immunotherapy. Front Immunol 10: 1147, 2019. https://doi.org/10.3389/fimmu.2019.01147

MENON MC, HEEGER PS: Donor SIRP-alpha polymorphisms: widening the innate-to-adaptive continuum in allograft rejection. Kidney Int 92: 1305-1308, 2017. https://doi.org/10.1016/j.kint.2017.10.006

MERINO A, BUENDIA P, MARTIN-MALO A, ALJAMA P, RAMIREZ R, CARRACEDO J: Senescent CD14+CD16+ monocytes exhibit proinflammatory and proatherosclerotic activity. J Immunol 186: 1809-1815, 2011. https://doi.org/10.4049/jimmunol.1001866

MIN D, BROOKS B, WONG J, AAMIDOR S, SEEHOO R, SUTANTO S, HARRISBERG B, YUE DK, TWIGG SM, MCLENNAN SV: Monocyte CD163 is altered in association with diabetic complications: possible protective role. J Leukoc Biol 100: 1375-1383, 2016. https://doi.org/10.1189/jlb.3A1015-461RR

MONNERET G, VENET F: Sepsis-induced immune alterations monitoring by flow cytometry as a promising tool for individualized therapy. Cytometry B Clin Cytom 90: 376-386, 2016. https://doi.org/10.1002/cyto.b.21270

OLDENBORG PA: CD47: A cell surface glycoprotein which regulates multiple functions of hematopoietic cells in health and disease. ISRN Hematol 2013: 614619, 2013. https://doi.org/10.1155/2013/614619

PASSOS LS, GAZZINELLI-GUIMARAES PH, OLIVEIRA MENDES TA, GUIMARAES AC, SILVEIRA LEMOS DD, RICCI ND, GONCALVES R, BARTHOLOMEU DC, FUJIWARA RT, BUENO LL: Regulatory monocytes in helminth infections: insights from the modulation during human hookworm infection. BMC Infect Dis 17: 253, 2017. https://doi.org/10.1186/s12879-017-2366-0

PENGAM S, DURAND J, USAL C, GAUTTIER V, DILEK N, MARTINET B, DAGUIN V, MARY C, THEPENIER V, TEPPAZ G, RENAUDIN K, BLANCHO G, VANHOVE N, POIRIER N: SIRPalpha/CD47 axis controls the maintenance of transplant tolerance sustained by myeloid-derived suppressor cells. Am J Transplant 19: 3263-3275, 2019. https://doi.org/10.1111/ajt.15497

RAVENHILL BJ, SODAY L, HOUGHTON J, ANTROBUS R, WEEKES MP: Comprehensive cell surface proteomics defines markers of classical, intermediate and non-classical monocytes. Sci Rep 10: 4560, 2020. https://doi.org/10.1038/s41598-020-61356-W

REINKE P, VOLK HD: Diagnostic and predictive value of an immune monitoring program for complications after kidney transplantation. Urol Int 49: 69-75, 1992. https://doi.org/10.1159/000282398 
ROGACEV KS, ZAWADA AM, HUNDSDORFER J, ACHENBACH M, HELD G, FLISER D, HEINE GH: Immunosuppression and monocyte subsets. Nephrol Dial Transplant 30: 143-153, 2015. https://doi.org/10.1093/ndt/gfu315

SEKERKOVA A, KREPSOVA E, BRABCOVA E, SLATINSKA J, VIKLICKY O, LANSKA V, STRIZ I: $\mathrm{CD} 14+\mathrm{CD} 16+$ and $\mathrm{CD} 14+\mathrm{CD} 163+$ monocyte subpopulations in kidney allograft transplantation. BMC Immunol 15: 4, 2014. https://doi.org/10.1186/1471-2172-15-4

STRIZOVA Z, VACHTENHEIM J JR, SNAJDAUF M, LISCHKE R, BARTUNKOVA J, SMRZ D: Tumoral and paratumoral NK cells and CD8(+) $\mathrm{T}$ cells of esophageal carcinoma patients express high levels of CD47. Sci Rep 10: 13936, 2020. https://doi.org/10.1038/s41598-020-70771-y

STURGE J, TODD SK, KOGIANNI G, MCCARTHY A, ISACKE CM: Mannose receptor regulation of macrophage cell migration. J Leukoc Biol 82: 585-593, 2007. https://doi.org/10.1189/jlb.0107053

TARIQUE AA, LOGAN J, THOMAS E, HOLT PG, SLY PD, FANTINO E: Phenotypic, functional, and plasticity features of classical and alternatively activated human macrophages. Am J Respir Cell Mol Biol 53: 676-688, 2015. https://doi.org/10.1165/rcmb.2015-0012OC

ULRICH C, HEINE GH, GERHART MK, KOHLER H, GIRNDT M: Proinflammatory CD14+CD16+ monocytes are associated with subclinical atherosclerosis in renal transplant patients. Am J Transplant 8: 103-110, 2008. https://doi.org/10.1111/j.1600-6143.2007.02035.x

VAN DEN BERK JM, OLDENBURGER RH, VAN DEN BERG AP, KLOMPMAKER IJ, MESANDER G, VAN SON WJ, VAN DER BIJ W, SLOOF MJ, THE TH: Low HLA-DR expression on monocytes as a prognostic marker for bacterial sepsis after liver transplantation. Transplantation 63: 1846-1848, 1997. https://doi.org/10.1097/00007890$\underline{199706270-00026}$

VAN DEN BOSCH TPP, HILBRANDS LB, KRAAIJEVELD R, LITJENS NHR, REZAEE F, NIEBOER D, STEYERBERG EW, VAN GESTEL JA, ROELEN DL, CLAHSEN-VAN GRONINGEN MC, BAAN CC, ROWSHANI AT: Pretransplant numbers of $\mathrm{CD} 16(+)$ Monocytes as a novel biomarker to predict acute rejection after kidney transplantation: A pilot study. Am J Transplant 17: 2659-2667, 2017. https://doi.org/10.1111/ajt.14280

VEILLETTE A, CHEN J: SIRPalpha-CD47 Immune checkpoint blockade in anticancer therapy. Trends Immunol 39: 173-184, 2018. https://doi.org/10.1016/j.it.2017.12.005

VEREYKEN EJ, KRAAIJ MD, BAAN CC, REZAEE F, WEIMAR W, WOOD KJ, LEENEN PJ, ROWSHANI AT: A shift towards pro-inflammatory CD16+ monocyte subsets with preserved cytokine production potential after kidney transplantation. PLoS One 8: e70152, 2013. https://doi.org/10.1371/journal.pone.0070152

WANG GQ, ZHANG Y, WU HQ, ZHANG WW, ZHANG J, WANG GY, XIAO SC, XIA ZF: Reduction of CD47 on monocytes correlates with MODS in burn patients. Burns 37: 94-98, 2011. https://doi.org/10.1016/j.burns.2010.04.007

WOHLFAHRTOVA M, TYCOVA I, HONSOVA E, LODEREROVA A, VIKLICKY O: Molecular patterns of subclinical and clinical rejection of kidney allograft: quantity matters. Kidney Blood Press Res 40: 244-257, 2015. https://doi.org/10.1159/000368500

XU M, WANG X, BANAN B, CHIRUMBOLE DL, GARCIA-AROZ S, BALAKRISHNAN A, NAYAK DK, ZHANG Z, JIA J, UPADHYA GA, GAUT JP, HIEBSCH R, MANNING PT, WU N, LIN Y, CHAPMAN WC: AntiCD47 monoclonal antibody therapy reduces ischemia-reperfusion injury of renal allografts in a porcine model of donation after cardiac death. Am J Transplant 18: 855-867, 2018. https://doi.org/10.1111/ajt.14567

XUE D, HE X, ZHOU C, XU X, XU R, XU N: Correlation between CD14+CD16++ monocytes in peripheral blood and hypertriglyceridemia after allograft renal transplantation. Transplant Proc 45: 3279-3283, 2013. https://doi.org/10.1016/j.transproceed.2013.08.022

YURYEVA K, SALTYKOVA I, OGORODOVA L, KIRILLOVA N, KULIKOV E, KOROTKAYA E, IAKOVLEVA Y, FEOKTISTOV I, SAZONOV, RYZHOV S: Expression of adenosine receptors in monocytes from patients with bronchial asthma. Biochem Biophy Res Commun 464: 1314-1320, 2015. https://doi.org/10.1016/j.bbrc.2015.07.141

ZHAO D, ABOU-DAYA KI, DAI H, OBERBARNSCHEIDT MH, LI XC, LAKKIS FG: Innate allorecognition and memory in transplantation. Front Immunol 11: 918, 2020. https://doi.org/10.3389/fimmu.2020.00918 